Philipine Journal of Psychology, 2018, 51(1), 121-154

Copyright @ 2018 Psychological Association of the Philippines

\title{
Sanctification of Adolescence: A Qualitative Analysis of Thriving Among Filipino Youth With Religious Sparks
}

\author{
Jet U. Buenconsejo \\ Colegio de San Juan de Letran \\ Ateneo de Manila University
}

Developmental systems theories have linked religiosity and spirituality with positive youth development (PYD), particularly "thriving". Thriving involves the identification of one's deepest interest or passion in life (termed as "spark") and being nurtured by an environment that supports, encourages, and develops this spark. Considering the need to understand the underlying mechanisms and processes of thriving in culturally, geographically, and racially diverse contexts of religion and spirituality, this study delved into the transcendental experiences of Filipino adolescents. Using the strategies and techniques of interpretative phenomenological analysis (IPA), the researcher interviewed 11 male Filipino Roman Catholics, aged 15 to 20 years old, who were able to identify a religious spark and are active members of a social group that supports their sparks. Results revealed five overarching themes: (a) perception of the nature of spark; (b) family and social groups as providers of guidance and support; (c) religious spark as source of positive experiences; (d) religious spark as source of negative experiences; and (e) compromises and adjustments amidst constancy of spark. Transcendence together with unconditional familial acceptance and appreciation have been found to be very crucial and salient in facilitating thriving. Theoretical and practical implications in promoting PYD are discussed.

Keywords: adolescent thriving, interpretative phenomenological analysis, positive youth development, religion and spirituality

Correspondence concerning this article can be addressed to Jet U. Buenconsejo. Email: jet.uy.buenconsejo@gmail.com. 
Over the past decades, studies on adolescent development in Psychology have focused on how to prevent young people from committing risky and problematic behaviors (Scales, Benson, \& Roehlkepartain, 2011). Psychologists have characterized this developmental stage as a critically turbulent phase in one's life, a make-it or break-it point towards healthy adulthood (King et al., 2005). However, with the emergence and growing popularity of positive psychology (Seligman \& Csikszentmihalyi, 2000) came a new perspective in understanding adolescent development. Positive youth development or PYD acknowledges that young people are capable of contributing something useful to themselves, to others, and to their communities (Hershberg, DeSouza, Warren, Lerner, \& Lerner, 2014). Instead of being seen as "problems to be solved" or "patients to be cured," PYD upholds adolescents as "resources to be developed," highlighting their strengths and potentialities towards becoming healthy adults (Bowers, Geldhof, Johnson, Lerner, \& Lerner, 2014; King et al., 2005; Lerner, Dowling, \& Anderson, 2003; Lerner, von Eye, Lerner, Lewin-Bizan, \& Bowers, 2010).

\section{Thriving as a Concept of PYD}

Thriving, a relatively new construct in PYD, can be described both as a status and a dynamic process where an adolescent is currently situated in the developmental continuum (Benson \& Scales, 2009; Scales et al., 2011). The concept of thriving posits that young people who are able to identify their deepest passions in life, termed as "sparks," and are nurtured by a healthy environment that supports, encourages, and develops these sparks, tend to develop positively during the second decade of life. According to Lerner and his colleagues (2010), the bi-directional interplay between an individual and his or her environment is the factor that facilitates adolescent thriving. If the young person's sparks are in parallel with the needs of his or her society and the resources that it can offer, then thriving can be optimized. It can be said that the mutual relationship between an individual and his or her ecological system allows each entity to benefit from and contribute to each other.

However, one should not confuse thriving with resilience, happiness, flourishing, or competence. Benson and Scales (2009) distinguished thriving from other developmental constructs of PYD. Accordingly, thriving is more than just "being okay," that is, it is more than just the acquisition of normal developmental competencies or the absence of psychological and behavioral problems. Thriving involves making significant contributions to themselves and to their specific 
ecologies, to their families, peers, and communities. It is about enabling one's spark to serve as an impetus in making a positive contribution to humanity, desiring to make the world a better place. Moreover, thriving comes with a sense of connection with a transcendent or sacred force that animates and motivates a young person to care for others and make a contribution to his or her society. In so doing, the adolescent's focus is not only centered on his or her personal world but involves others as well. Prosociality and spirituality therefore are the distinctive features of adolescent thriving from the rest of the concepts of PYD (Benson \& Scales, 2009).

Religious and spiritual experiences have been quantitatively linked with positive youth development, particularly in facilitating thriving (King, Ramos, \& Clardy, 2013). Religious identification among adolescents demonstrated a positive relationship with personal meaning and prosocial personality, two important components of PYD that serve as ideological grounds in moving towards early adulthood (Furrow, King, \& White, 2004). Beliefs and philosophies advocated by different religious institutions provide a sense of identity that is generally characterized by a genuine concern for others, desiring the common good of everyone in one's society (King, 2003). Erikson (1964, 1965, \& 1968, as cited in King, 2003) acknowledged the important role of religion in the process of identity development. According to him, religion is the oldest and most enduring institution known to mankind that promotes fidelity to one's identity and ideology in life, the core strength of the fifth stage of his theory on psychosocial development - identity versus identity confusion. Spirituality, which is considered distinct from religiosity, was found to statistically mediate adolescent thriving between the individual and his or her ecological context, motivating the young person to make a significant contribution and manifest an exemplary adolescent development (Dowling et al., 2004). Spirituality enables a young person to experience transcendence which involves moving beyond one's self and connecting with an external force, something greater or larger than one's self (Benson, Roehlkepartain, \& Rude, 2003). Studies have shown that compared to other developmental contexts, that is, secular or non-religious contexts, faith-based organizations are unique in facilitating thriving because of the distinct philosophies, interactions, experiences, and developmental resources that they provide to adolescents (Good \& Willoughby, 2011; Good, Willoughby, \& Fritjers, 2009; Larson, Hansen, \& Moneta, 2006).

Overall, both religiosity and spirituality provide a fertile ground where an adolescent can have access to beliefs, ideologies, and practices that promote thriving. Nonetheless, there is much area to be explored 
in this field of psychology. Although quantitative relationships have already been established between adolescent thriving and one's religiosity and spirituality, there is still a need to understand their underlying mechanisms and processes across various contexts and situations (King et al., 2013).

\section{Religiosity and Spirituality: Points of Convergence and Divergence}

Although the distinction between religiosity and spirituality is not the primary concern of this paper, this section provides the readers a fuller sense of these often vague and overlapping concepts. Initially, the words religiosity and spirituality were used by researchers and practitioners in Psychology interchangeably (Koenig, McCullough, \& Larson, 2001, as cited in King et al., 2013). However, with the developments in the field and a deeper understanding of individual and social experiences from different cultures and ethnicities, the two words gained their own meaning and definition (Pargament, Mahoney, Exline, Jones, \& Shafranske, 2013). According to Koenig and his colleagues (2001, as cited in King et al., 2013), religiosity speaks of an adherence to a set of institutional beliefs, practices, and traditions that aim to facilitate closeness with a sacred or transcendent being. On the other hand, spirituality pertains to one's personal relationship with a sacred or transcendent being that may or may not occur in the context of religion. Although these constructs are non-isomorphic or non-identical, both are concerned with the search for the sacred or an ultimate truth in life (Pargament et al., 2013). Although not limited to a supreme being, the sacred or this ultimate truth in life is usually attributed with divinelike qualities or characteristics such as ultimacy, transcendence, omnipotence, and boundlessness.

Authors have cautioned researchers and practitioners about overly dichotomizing these two constructs since religion may include spirituality and spirituality may occur in the context of religion (King et al., 2003; Pargament et al., 2013). Overly simplistic definitions of religiosity and spirituality would inhibit a person from understanding the complexity and nuances of these experiences. Pargament (1999, as cited in Pargament et al., 2013) noted that there is a tendency to view religiosity as exclusively institutional while spirituality is seen as solely personal. With more and more adults and adolescents identifying themselves as "spiritual-but-not-religious," the public tends to have a polarized and constricted view of religion as bad and spirituality as good. Nevertheless, one has to consider that religion can be a great source of spirituality for many and that both experiences almost 
always overlap with each other in reality (Hill et al., 2000, as cited in Pargament et al., 2013).

\section{The Filipino Experience of Religiosity and Spirituality}

While western authors seem to be concerned in clearly defining and differentiating religiosity from spirituality, the opposite appears to be true here in the Philippines where both constructs are said to be intertwined and hardly separable. For Filipinos, spirituality is anchored on religiosity for it is through their institutional and cultural beliefs, practices, and traditions that they experience a sense of connection with the sacred or the transcendent (Yabut, 2013). The same also appears to be true among Filipino adolescents' perceptions. In one qualitative study conducted by Mansukhani and Resurreccion (2009), Filipino adolescents, aged 15 to 17 years old, described a spiritual person as both spiritual and religious who plays an important role in their religious community. These descriptions further blur the distinction between religiosity and spirituality among Filipinos. In order to deeply and truly understand the complex phenomena of religiosity and spirituality among Filipino adolescents, the researcher believes that the two concepts should be studied collectively within this particular context.

In the Philippines, almost all of its population affiliate themselves with a particular religious institution (99.92\%) with 80.53\% identifying themselves as Roman Catholics (Philippine Statistics Authority, 2016). It is noteworthy that the majority ( $85 \%$ ) of Filipinos continue to consider religion as an important aspect of their lives even up to the present (Social Weather Stations, 2017). In a survey conducted among Filipino Catholic youth in 2013, it was reported that $97.40 \%$ perceive religion as something important in their lives, while $85.40 \%$ said they are religious, primarily influenced by their parish priests, mothers, and co-members in church-based youth organizations. Likewise, $79.40 \%$ said they attend weekly religious services (Catholic Educational Association of the Philippines, 2013). On the surface level, these figures give a general description of Filipino adolescents' religious and/or spiritual profile. However, compared to the vast number of researches in the west, there seems to be a rarity of studies dealing with adolescent religiosity and spirituality in the Philippine context that consider the multiplicity and diversity of the participants' subjective experiences (Mansukhani \& Resurreccion, 2009). This study tries to address these issues by understanding the depth and breadth of adolescent thriving in the context of Filipino religiosity and spirituality. 


\section{Theoretical Framework}

The concept of thriving is basically grounded on the relational developmental systems theory (Lerner et al., 2003; Lerner, Lerner, von Eye, Bowers, \& Lewin-Bizan, 2011; Lerner et al., 2010) which states that the bi-directional interaction between the individual and his or her environment is vital in the development of a healthy young person. It posits that all young people have the potential for healthy and positive development and change, termed as "relative plasticity," provided that they grow in contexts rich in assets and resources that can be combined and aligned with the adolescents' strengths and capacities, termed as "developmental regulation." Lerner and his colleagues (2011) acknowledged that both the adolescent (individual factor) and his or her environment (contextual factor) possess valuable strengths and assets that they can share with and contribute to each other. This basic tenet of this theory suggests that the combination and alignment of the adolescent's strengths (e.g., a young person's specific skill, talent, or interest) with the resources that his or her family, school, or community can offer (e.g., a group leader's capacity to provide an environment or atmosphere that enhances and directs an adolescent's talents) facilitate the development of thriving. Over time, it is assumed that the mutually beneficial interactions between a developing individual and a supportive ecology result in healthy life trajectories characterized by the presence of positive developmental outcomes, such as competence, confidence, connection, character, and caring, also termed as the "Five C's of PYD" (Eccless \& Gootman, 2002, as cited in Lerner et al., 2011). Other authors suggest that generosity, hope, life satisfaction, prosocial orientation, positive emotionality, self-regulation, and spirituality are also indicators of thriving (Benson \& Scales, 2009). Young people exhibiting these positive characteristics become less likely to engage in risky and problematic behaviors, instead, they become capable of making significant contributions back to themselves and to their specific ecologies (Lerner et al., 2011).

Aside from the relational developmental systems theory, the researcher also made reference to the integrative paradigm of religion and spirituality as proposed by Pargament and his colleagues (2013) in the APA Handbook of Psychology, Religion, and Spirituality. Compared to overly narrow and overly broad definitions of religiosity and spirituality, this framework offers a non-reductionistic perspective of understanding these two terms without compartmentalizing them. It takes into account the multiplicity and diversity of people's religious and spiritual experiences, noting that these phenomena are multidimensional, multilevel, and multivalent. By multidimensional, 
it means that there are several pathways that lead to religiosity and spirituality, which include affective, behavioral, and cognitive responses occurring at different dimensions and stages of life. Religiosity and spirituality are also considered multilevel because such experiences and expressions do not occur in isolation. Rather, they are influenced by one's social, historical, and cultural contexts at particular developmental stages. Lastly, religiosity and spirituality are multivalent in that they may be helpful or harmful to a higher or lesser degree, incurring positive as well as negative consequences to individuals and groups. Depending on the situation, both concepts have the capacity to yield good and bad outcomes. Although the researcher acknowledges the distinctive characteristics of religiosity and spirituality, both concepts were studied collectively in this paper as this would yield a richer and deeper understanding of thriving, an understanding that is closer to the subjective realities and experiences of the participants.

\section{Context of the Current Study}

Considering the need to understand the underlying mechanisms and processes of this emerging and fascinating concept of thriving in culturally, geographically, and racially diverse contexts of religion and spirituality (King et al., 2013; Mansukhani \& Resurreccion, 2009), the study aims to explore how Filipino adolescents with religious sparks experience thriving in a particular social group. It is worth noting that majority of the studies on adolescent thriving have used cross-sectional survey research designs that have been dominated by middle to upper class samples from North America (Benson \& Scales, 2009; Hershberg et al., 2014). Furthermore, despite authors acknowledging the unique role of faith-based institutions in facilitating thriving, almost all studies on this area of positive youth development have focused on secular or non-religious contexts usually involving sparks related to academics, community service, leadership, performance and fine arts, as well as sports (Good \& Willoughby, 2011; Good et al., 2009; Larson et al., 2006). Taking into account the scarcity of qualitative researches that delve into understanding adolescent thriving in faith-based developmental contexts as well as the relative uniqueness of religiosity and spirituality in the Philippines, it is the intent of this research to explore the experiences of Filipino young people with religious sparks.

This paper defines a "religious spark" as a young person's deepest interest, hobby, or talent in life that is anchored in a specific set of institutional beliefs, practices, or traditions aimed at facilitating closeness with a sacred or transcendent being. Considering the 
multivalence of religiosity and spirituality, the researcher assumes that a religious spark may or may not ignite adolescent thriving. The researcher would like to maintain this "attitude of strangeness" towards the study so as to allow the natural emergence of complex and diverse meanings from the participants' experiences. Furthermore, as thriving is considered as a bi-directional interaction between the individual and his or her environment, the participant is expected to be an active member of a particular group that supports and provides opportunities for him or her to hone and develop a religious spark.

Consistent with the propositions of the relational developmental systems theory and the integrative paradigm of religion and spirituality, this study delved into the bi-directional process of thriving by understanding the lived experiences of young people with religious sparks (individual factor) as they interact with a particular social group (contextual factor) that supports, encourages, and develops these sparks. As shown in Figure 1, these experiences are embedded in the larger societal context of Filipino religiosity and spirituality. As such, the said phenomenon would be studied within this cultural atmosphere. The notion that religiosity and spirituality are multidimensional, multilevel, and multivalent would also be taken into account in undertaking this research. Specifically, the researcher aims to understand how religious sparks are experienced by looking at the meanings that the participants ascribe to their religious and/ or spiritual experiences, the influence of a religious spark on an adolescent's way of looking at society and life in general, their modes of interaction with supportive social groups, their significant contributions to these social groups, as well as the impact of these social groups to the participants themselves.

\section{METHOD}

A qualitative approach using the strategies and techniques of interpretative phenomenological analysis (IPA) (Eatough \& Smith, 2008; Smith \& Eatough, 2007; Smith \& Osborn, 2003) was employed by the researcher in undertaking this study. This approach was chosen because of its emphasis in exploring and understanding the lived experiences of a particular group of people as well as the meanings that they ascribe to these experiences. Aligned with the main objective of this study, IPA focuses on how participants make sense of their personal and social worlds as they experience a particular phenomenon (Smith and Osborn, 2003). This qualitative strategy of inquiry is concerned with what people are experiencing and how they are experiencing 


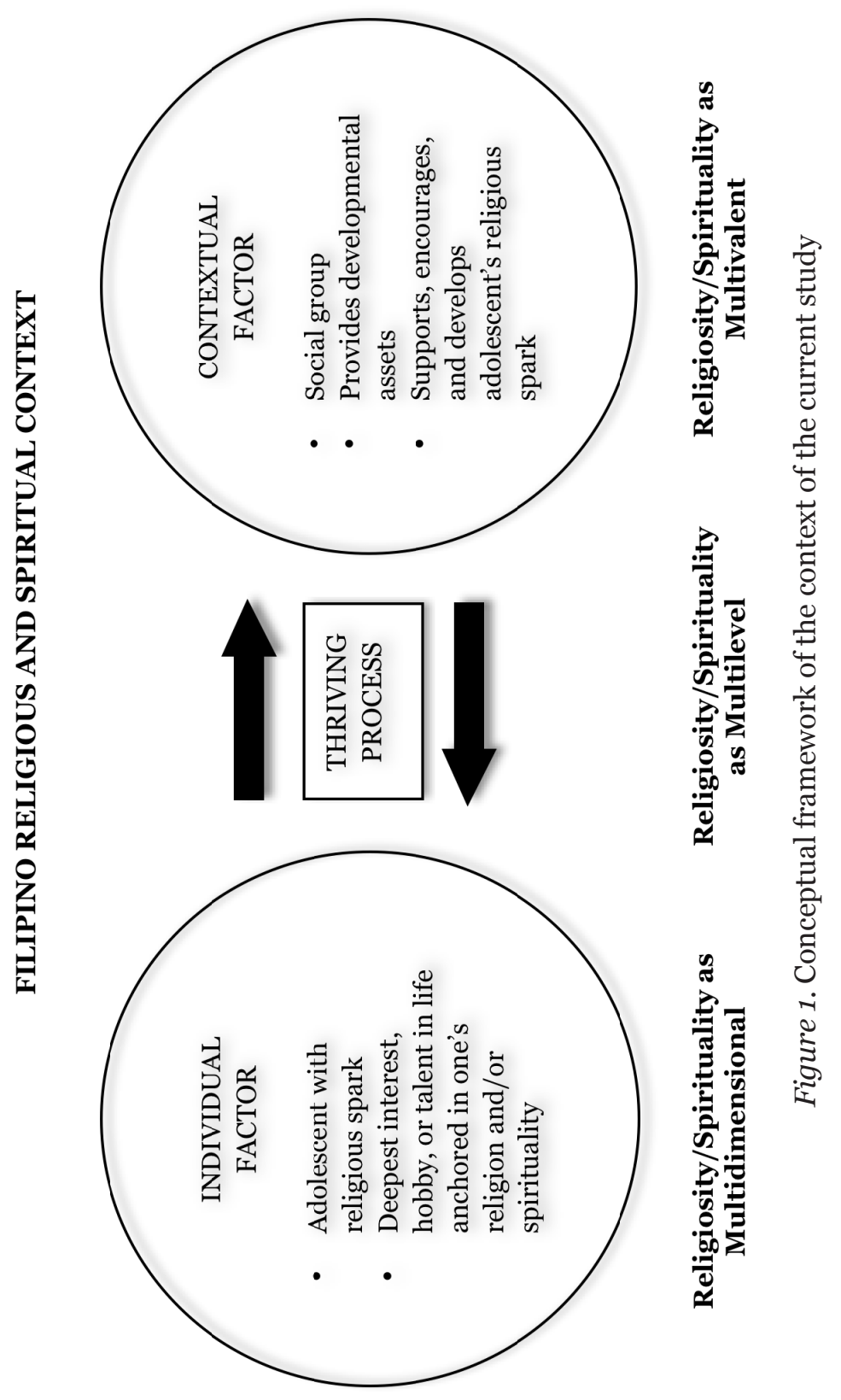


it, highlighting the importance of subjective experiences (Eatough \& Smith, 2008).

IPA espouses the views of social constructionism in that it acknowledges the importance of cultural and historical contexts in understanding the subjective experiences of people (Eatough \& Smith, 2008). IPA takes into account the environment where the individual is situated, the environment where the meaning or essence of a particular phenomenon is constructed. As such, the focus of IPA on identity construction and meaning making would enable the researcher to arrive at descriptions and interpretations that are capable of encapsulating the multiplicity and diversity of the phenomenon being studied. Overall, the strategies, foci, and assumptions posited by this approach gives direction to the objective of this study - to understand how Filipino adolescents with religious sparks experience thriving in a particular social context.

\section{Participants}

Eleven participants, aged 15 to 20 years old, were included in this study. Using purposive sampling, the researcher employed three selection criteria in recruiting participants. First, they should be able to identify a spark that is religious and/or spiritual in nature. A spark is a deep interest, hobby, or talent that a young person is most passionate about. It motivates, inspires, and directs his or her actions in life (Benson \& Scales, 2009; Scales et al., 2011). A spark can be considered religious and/or spiritual if it is anchored on a specific set of institutional beliefs, practices, or traditions (religiosity) aimed at facilitating closeness with a sacred or transcendent being (spirituality). Second, the participant should be an active member of a specific group of people which he or she thinks supports and encourages his or her religious and/or spiritual spark. Lastly, the researcher chose participants who were 15 to 20 years old at the time of the data collection. This age range was selected because the participants would be in the second half of the adolescent period and they would be better able to express and articulate their feelings and experiences regarding the phenomenon being studied. Moreover, Scales and his colleagues (2011) noted that certain differences exist between the periods of early adolescence and late adolescence in terms of thriving, particularly on developmental support and encouragement that they receive from their environments.

The participants were mainly recruited through the social networking website Facebook. Online advertisements asking 15- to 20-year-old adolescents to identify their deepest interests, hobbies, or 
talents in life were posted in online religious groups. However, this recruitment strategy did not yield much response from the members of these groups. Private massages were then sent to prospective participants asking them if they could identify their deepest interests, hobbies, or talents that they are most passionate about in life. This was done without mentioning any religious and/or spiritual cue. The challenge for the researcher was to allow the natural emergence of the religious and/or spiritual nature of their sparks. Those who were able to identify religious and/or spiritual sparks were asked to further describe and explain these sparks. Only prospective participants who met the three selection criteria were included in this study. Snowballing technique through referrals and suggestions from initial participants was also used by the researcher in order to arrive at the desired sample size. Although the researcher did not consider sex, religion, and academic background, the eleven participants who met the inclusion criteria were all male Roman Catholics. Two were in high school, eight were in college, most of whom were taking education programs, and one participant just dropped out from school at the time of the interview.

\section{Data Collection}

Each participant was individually interviewed for 40 to 90 minutes using a semi-structured interview protocol available in English and Filipino. Sample questions include "What are the things that you like to do the most?", "What are your interests or hobbies in life?", "How did this spark started?", "Can you recall the first time you experienced or felt this spark?", "Can you describe how was it like to live with this kind of spark?", "How did you become a member of this group?", and "What activities do you usually do with this group?" These questions were validated by two senior researchers. As suggested by Smith and Osborn (2003 ), funneling was used in interviewing the participants, starting from general questions going to specific ones. The interview sessions were conducted in a conducive place, free from any noise or distraction. Informed consent and permission to audio record the interview sessions were obtained from the participants. Parental consent was also secured for participants below 18 years old. The researcher made sure that the participants were at ease before starting the interview. 


\section{Data Analysis}

The steps and guidelines of IPA as suggested by Smith \& Osborn (2003) were followed by the researcher in undertaking the data analysis phase of the study. After transcribing the interview sessions, the researcher, together with another graduate psychology student who was oriented with the propositions and procedures of IPA, familiarized and immersed themselves with the data by reading and rereading the interview transcriptions of the eleven participants several times. This enabled the research team to have an "insider's perspective" (Conrad, 1987, as cited in Smith \& Osborn, 2003 ) towards the participants subjective realities and experiences. Initial codes, which include comments, observations, and reflections, were written on the lefthand margin of the transcript. These codes were then clustered into emerging themes on the right side. At this point, the research team compared their preliminary codes and themes with each other, spotting similarities and differences as well as locating points of convergence and divergence. Drawing from the work of Braun and Clarke (2006) on thematic analysis, some of the themes were combined to form overarching ones that subsumed minor themes; others were separated because of their distinctiveness and significance. This process was done by the research team in an idiographic manner, analyzing one case at a time. Each transcript was individually read and analyzed before arriving at the final list of overarching themes and their subthemes.

Unlike other phenomenological strategies and techniques, IPA gives emphasis on the active role of the researcher in interpreting the lived experiences of the participants. Here, the researcher is trying to make sense of the participants who are also interpreting their personal and social worlds. Both the researcher and the participants are involved in this two-way meaning making process called "double hermeneutic" (Smith \& Eatough, 2007). In order to ensure that the interpretation and analysis of the research team were indeed reflective of the experiences of adolescents with religious sparks, a recursive and iterative process of returning to the verbatim accounts and significant statements of the participants was done from time to time. In addition to that, a focus group discussion (FGD) was organized by the researcher wherein overarching themes and their subthemes were presented and described back to the participants. The FGD assessed whether they could relate with the themes or not. Necessary changes and revisions were made based on their comments, reflections, and thoughts. A paper trail documenting the entire research process was also kept by the researcher in order to track down the progress and development of the study. 


\section{RESULTS}

After employing the recursive and iterative process of IPA, the researcher arrived at five overarching themes that encapsulate the lived experiences of Filipino adolescents with religious sparks, namely, (a) perception of the nature of spark; (b) family and social groups as providers of guidance and support; (c) religious spark as source of positive experiences; (d) religious spark as source of negative experiences; and (e) compromises and adjustments amidst constancy of spark. As shown in Table 1, each overarching theme contains subthemes which are discussed thoroughly in the following paragraphs.

\section{Perception of the Nature of Spark}

This overarching theme pertains to how the participants perceive or view their religious sparks or what they consider as their deepest interest or passion in life. They are aware that their sparks have been with them ever since they were children, noting that it both came from a higher being and from their inner selves. A religious spark also provides them with a sense of identity, an identity that comes from one's self (internal) and from other people (external). This view is similar to the sources of religious spark, namely from the Divine (external) and from their inner selves (internal). Lastly, the participants perceive their sparks as an impetus to making a significant contribution to their social groups and to people who are in need. Sharing one's religious spark to others is seen as the fulfillment or completion of its essence.

Presence of sparks at an early age. The participants reported experiencing a strong inclination towards religiosity at an early age. Almost all of them said that they first got a sense of their religious sparks as early as three or four years old, although one participant reported identifying his deepest passion in life, which is being an altar server, at the age of ten. According to them, their childhood memories were characterized by curiosity and fascination towards religious beliefs, practices, and traditions done by their parents and other significant adults in their lives, particularly their grandmothers. This enthrallment often leads to observational learning or modeling wherein they would imitate or mimic religious expressions done by adults: "...maybe it was being implanted on my mind, maybe this is what I should do since adults are doing the same." Furthermore, they noted that their games during childhood always featured religious themes and ideas: “....when I was a child, I would place religious images on top of small cars, in a line similar to a procession..." Unlike other 
134 A Qualitative Analysis of Thriving

Table 1. Overarching Themes and Subthemes of the Lived Experiences of Filipino Adolescents With Religious Sparks

\begin{tabular}{|c|c|}
\hline Overarching Themes & Subthemes \\
\hline 1. Perception of the nature of spark & $\begin{array}{l}\text { a. Presence of sparks at an early age } \\
\text { b. Spark as coming from the Divine and } \\
\text { coming from within } \\
\text { c. Spark as an identity } \\
\text { d. Spark as something to be shared }\end{array}$ \\
\hline $\begin{array}{l}\text { 2. Family and social groups as } \\
\text { providers of guidance and support }\end{array}$ & $\begin{array}{l}\text { a. The permissive and restrictive roles of } \\
\text { one's family } \\
\text { b. Social groups as extensions of one's family }\end{array}$ \\
\hline $\begin{array}{l}\text { 3. Religious spark as source of } \\
\text { positive experiences }\end{array}$ & $\begin{array}{l}\text { a. Development and maturity } \\
\text { b. Uniqueness and privilege } \\
\text { c. Joy and fulfillment } \\
\text { d. Courage and persistence } \\
\text { e. Self-preservation }\end{array}$ \\
\hline $\begin{array}{l}\text { 4. Religious spark as source of } \\
\text { negative experiences }\end{array}$ & $\begin{array}{l}\text { a. Feelings of being different and alone } \\
\text { b. Discrimination from others } \\
\text { c. Feelings of fear and despair } \\
\text { d. Conflicts participants have encountered } \\
\text { with their families, groups, and selves }\end{array}$ \\
\hline $\begin{array}{l}\text { 5. Compromises and adjustments } \\
\text { amidst constancy of spark }\end{array}$ & $\begin{array}{l}\text { a. Changing of groups } \\
\text { b. Periods of inactivity } \\
\text { c. Identification of another way of expressing } \\
\text { one's spark }\end{array}$ \\
\hline
\end{tabular}

children, they would prefer religious images over other toys like action figures: "...others like Gundam, what they like is Beyblade, toys like that. I also like those toys, but I prefer religious stuff more." Although their attraction to religiosity initially sprouted from superficial and trivial reasons like the aesthetic appearance of a religious image or the novelty of a particular belief, practice, or tradition, their religious sparks eventually gained deeper meaning and significance as they learned new things and encountered new people in their social groups.

Spark as coming from the Divine and coming from within. The participants are aware that their religious sparks are coming from two distinct sources: from the Divine and from their inner selves. This awareness comes with an understanding that one's spark is something that was given but at the same time it is also seen as something that one was born with, similar to a natural predisposition. Hence, a religious spark has external (God) and internal sources (self), both of which are reflected in the participants' accounts. First, they 
described their religious sparks as a call coming from God that they believe they should answer or respond to: "...maybe that spark came from God who particularly chose me." It is viewed as a mission and a responsibility given by the Divine, a commitment or a vow that needs to be fulfilled as a means of expressing gratitude to God and reciprocating His love. "That is why if God loves you, you should return to Him that love." The participants appear to equate their religious sparks with religiosity and spirituality themselves since they see their interests as means that facilitate closeness with a sacred or transcendent being. As mentioned, the participants also expressed their sparks as something that naturally comes from within. According to them, it was never forced or dictated by family members or other people. As such, it is intrinsically motivated and done for its own sake:

She (grandmother) never forces me to join the procession, she never forces me attend the Mass, she never forces me to attend the Dawn Mass and pray the rosary. She never forces me to do such things but I do it.

Spark as an identity. The identity provided by a religious spark can be seen both as a self-identity and a label coming from others. Similar to its sources, this identity is internally (self) and externally (other people) produced. The participants expressed a sense of awareness and a feeling of certainty towards their sparks as their real and true selves, something which they are good at: "I would completely claim that this is a spark...I know deep inside me, I know..." They also described it as something inseparable from their personalities, something that completes them: "I can never separate, I cannot separate myself from the church...Because my heart is there. My life is also there in the church." Some participants went further into expressing their sparks as their life and their world, comparing it to the act of breathing, something that they cannot live without: "...I can really see that this is where I am going to live, this is also where I am going to die..." However, the participants also narrated that this spark is also used by others in expressing their expectations and associations about religious people, particularly in being righteous and saintly all the time. Somehow, they are given a brand, a label, or a standard that being religious means being virtuous always: "...if you are in the church, you are upright, you are a moral person..." Because of their religiosity, their faults and mistakes are easily pinpointed by other people, especially by their parents. One participant recounted how his mother would use his religious inclination whenever she would reprimand him: "You like things like that but your attitude is contrary!" These statements usually bring feelings of embarrassment and guilt but they also see it as a challenge to strive for goodness and 
holiness. Nevertheless, there is a sense of appreciation of this identity among the participants. They take pride in expressing their real and true selves despite other people's perception of them: “...the best way is to express yourself, who you really are, what you like...you do not need to change anything about yourself for others to like you. They have to like you for who you really are."

Spark as something to be shared. This perception of religious spark entails transmitting their faith into action by helping and making a significant contribution to people and groups around them. Knowledge of and devotion to the lives of Christ, Mary, and the saints are viewed incomplete and flawed if they do not lead to the imitation of their examples and virtues: "...there is a corresponding action to that, you do not just know it..." For them, having a religious spark means practicing and living the essence and spirit of their religion, which is charity by being of service to others. One participant said, "A treasure is not a treasure unless you share it. Love is not love unless you make it felt..." This desire to serve involves a sense of awareness that something can be changed or improved after identifying a specific problem or dilemma in their social groups. Contributions are usually made by suggesting and implementing projects and by mentoring younger members of their groups, sharing their knowledge and experience with them. One participant compared this act to the light given by a candle, "...we need to be a candle that shall give light to our neighbor..." Since the participants see their sparks as a call, a mission, or a responsibility from God, they feel obliged to respond to it by serving the people around them, particularly those who are in need.

\section{Family and Social Groups as Providers of Guidance and Support}

The participants consider their families and social groups as the primary contexts wherein guidance and support for their religious sparks are provided. They described their families as performing permissive and restrictive roles towards their sparks. It therefore allows and limits the expression of their deepest interest or passion in life. Social groups supporting their sparks are seen by the participants as extensions of their families wherein a sense of community, affection and appreciation, as well as good role models and mentors are provided. Nonetheless, although social groups may supplement the guidance and support from one's family, they cannot totally replace its primary and necessary role, particularly the parents, in facilitating thriving. This will be discussed in more detail in the Discussion.

The permissive and restrictive roles of one's family. The 
role of the family can be summed up into two points: it allows and limits the expression of religious spark. The participants recounted how they felt supported through the affirmation, concern, and interest that their families would show them. These acts of recognition and acceptance had a great impact on them, no matter how simple or subtle the actions were: "You would just feel it whenever she (mother) would give you a transportation fare, ummm, she would not scold you for going home late at night because she knows where you are..." Aside from that, almost all participants emphasized the important role of their grandmothers in the formation and development of their religious sparks. They would often recall their outward expressions of religiosity and spirituality back when they were children, which they consider as something that ignited their sparks. They also noted the presence of religious and spiritual traditions in their families and communities, stating that it was something normal and customary. On the other hand, the family also limits and controls the expression of religious spark by constantly reminding the participants of their priorities in life, especially their studies. One of the fathers of the participants said, "Continue doing that as long as you know that it is good, just continue, but if you realize that your actions are becoming too much, that something is already wrong, then stop it." However, these limitations sometimes lead to restrictions from parents of participants who cannot prioritize their studies because of their religious sparks. One of the mothers of the participants angrily prohibited her son from going to church after failing three consecutive grading periods saying, "Do not go to the church anymore! Never go to the church! Fix your entire life!"

Social groups as extensions of one's family. More than a platform where they can freely express their religious sparks and showcase their talents, social groups are seen by the participants as extensions of their families primarily because of the important roles that they play in the adolescents' lives. Based on their accounts, these groups have three main roles, (a) they give a sense of community, (b) they provide affection and appreciation, and (c) they offer good role models and mentors.

Upon joining a social group that supports their religious sparks, the participants came to the realization that they are not alone, that there are other people like them, peers who share the same religious interest and passion in life. Eventually, these social groups gave them a sense of brotherhood and affiliation wherein cooperation among its members is fostered. One of the participants recounted, "We were able to form a clique then we would go to different churches, we would find religious craftsmen."

For some, social groups supplement the affection and appreciation 
that their families or peers cannot adequately give. Somehow, these groups provide the understanding that some participants are yearning for, although feelings of grudge or bitterness are not harbored in their families:

...I have had several foster mothers in the church...I have also treated others as my siblings, welcome, you feel welcomed, loved. The church really became my home because people there understand me but I always pray that things will be fine for my family eventually.

Within these groups, participants feel appreciated, important, and needed by its leaders and members through the creative activities and projects that they would suggest or implement: “...I feel very important in the church that is why I feel like, without bragging, if I would be gone, I would be a great loss for the church." Affection and appreciation from the participants' groups are shown through the recognition and acceptance of their religious sparks. They are provided with frequent encouragements in expressing and developing their interests and passions in ways that are beneficial for them and the people in their groups.

Social groups also offer good role models and examples whom the participants can imitate or emulate. One participant narrated, “...He (group coordinator) also told us that school and serving in the church should be balanced and I saw that in him because now, he has four professional licenses..." Group leaders are also seen by the participants as parental figures, guiding, directing, and correcting their actions and mistakes. One participant recounted that he found the guidance he was looking for in one of the senior members of their group since his father died when he was just three years old.

\section{Religious Spark as Source of Positive Experiences}

Positive experiences are generally brought about by freely expressing one's religious spark and gaining acceptance, recognition, and support from one's family, social group, and self. In general, the participants reported favorable attitudes towards their sparks, stating that it has brought them satisfaction and completion in life. Although problems and difficulties would arise, they continue to value and place great importance in their religious sparks. The positive experiences that the participants narrated include (a) development and maturity, (b) uniqueness and privilege, (c) joy and fulfillment, (d) courage and persistence, and (e) self-preservation.

The participants reported gaining a deeper understanding of the significance and meaning of their religious sparks by learning new 
things and meeting new people. According to them, their spiritual and prayer lives became more profound, attaining a sense of maturity which they attribute to the trials and challenges in their lives: "There is a deeper meaning now with what you are doing because of the long process that you have undergone." Awareness and appreciation of one's uniqueness and individuality were also observed among the participants. They felt privileged and special compared to other people, noting that religiosity is quite uncommon among their peers: "...I am more blessed than them. What they have is temporal, mine is spiritual." Also, opportunities provided by their social groups make them feel closer to God, which they consider as a humbling and overwhelming experience: “...it is a big opportunity to be able to serve God..." Aside from that, the participants also expressed feelings of extreme joy and fulfillment because of their religious sparks, relieving them of their worries and anxieties in life. The unconditional acceptance and appreciation from their families and social groups also enhance these feelings of joy and fulfillment. This unexplainable happiness is coupled with excitement and anticipation of continuously doing or expressing their sparks despite encountering hardships, difficulties, and challenges. One participant said,

You do not know why, when in fact you are just serving at the altar, you are ordered to do things, sometimes you are even scolded, then I told myself I do not know, what I know is that I really like it.

In times of trials and tribulations, particularly problems and conflicts involving their families, social groups, and school-related activities, the participants would always draw strength and inspiration from the sufferings of Christ or the lives of the saints. A participant remembered telling himself, "You are here for God. Why, did Christ complain when he was being persecuted? No." Mary is also seen as a maternal figure who is very much concerned about them. The spark itself is a source of courage and perseverance in expressing their deepest interest and passion in life: "What is important there is doing what you want and what God wants." The religious sparks of the participants have also performed a preventive role in their lives by sparing them from risky, problematic, and negative behaviors. For them, their inclination towards religion saved them from delinquency, preserving their moral uprightness. One participant narrated that his spark spared him from committing suicide: “...for all I know I might be a criminal, or I might even kill myself. I have had tendencies before to commit suicide, but that spark somehow stopped me.” A religious spark also acts as a conscience and a guide that gives direction, meaning, and purpose in the adolescent's life: “...I can say I am pursuing the right track because, there is goodness in the church." 


\section{Religious Spark as Source of Negative Experiences}

The participants noted that the presence of a religious spark in one's life can also be a source of negative experiences. These undesirable experiences are usually associated with rejection and lack of appreciation or support from the participants' significant others, particularly their families and social groups. Harsh judgments from and misunderstandings with other people can also cause adverse feelings on the part of the adolescent. In general, negative experiences can be clustered into four subthemes, namely, (a) feelings of being different and alone; (b) discrimination from others; (c) feelings of fear and despair; and (d) conflicts participants have encountered with their families, groups, and selves.

Because of their religious inclination, which is quite uncommon or unusual among their peers, the participants would often feel different and alone. As children, few wanted to play with them as they were considered odd and eccentric by their peers. Unlike their siblings or cousins, the participants noted that they are the only one in their families with this kind of interest. It was also difficult for them to find someone whom they can share or exchange ideas with because only few people can relate with them: "Then there are sad times because I am the only person who can understand myself that I have no one to share these things with..." Some participants also recalled experiencing discrimination and bullying because of their religious sparks. Other people, including some of their family members, find their interest strange and weird, describing it as something creepy. They were even told crazy and insane by other people. At times, their integrity as a religious person is questioned or criticized by others. One participant who was bullied because of his spark said, "Of course, it is not easy because there are people who criticize you, there are people who will question you..." Experiences of discrimination and bullying usually lead to feelings of fear and despair. Some participants expressed their apprehension or anxiety of openly expressing their sparks because they do not want to be judged or humiliated:

...it was painful in the heart, it was like being stabbed by a knife in the heart that I was telling myself that this is, this is the consequence of stopping, that I was telling myself that I wanted to return but the fear of being criticized was there, I might be belittled again.

Some of them also came to a point of wanting to abandon or give up their religious sparks in order to fit in their environments: “...I wanted give up, I just wanted to be an ordinary person..."

Included also in the theme of negative experiences are conflicts 
and inconsistencies that the participants experienced with their (a) families, (b) social groups, and (c) selves. Some of the participants reported being discouraged and even forbidden by their own families in expressing their sparks, partly because some of them were starting to get failing grades at school. Although tolerated, parents who are not religious or who are always busy at work do not seem to understand their child's inclination: "I cannot say that I am supported by my family because they do not understand the, situation, in the church...they are not members of any church organization. They are working. They are very busy at work." This conflict further enhances one's feeling of being different from other family members.

In terms of their social groups, the participants narrated experiencing frustration and disappointment over the rude attitude of some group members and even leaders: "...I am not enjoying whenever I am in the parish because you would see their inconsistent attitude..." They also reported issues involving gossip and defamation that really saddened and discouraged them to the point of considering leaving their groups.

Conflicts and inconsistencies also arise within themselves. Some participants narrated experiencing difficulties in setting their priorities in life. Since they are both studying and serving in the church, school is often sacrificed in favor of their religious sparks. In fact, some of them incurred low grades at school because they could not balance their responsibilities as a church volunteer and as a student: "I was always at the church that it already affected my studies." In fact, one participant was asked by his mother to withdraw from schooling because of a series of failing grades. Health complications were also reported by some of the participants because of fatigue in doing church-related activities: "...I was at the church the entire day to the point that I have starved myself. I fainted because of so much fatigue." Conflict with one's self is also manifested in the different, sometimes opposite, attitudes that they exhibit at church, home, and school. The participants narrated that they excel in activities that are related to their religious sparks but not in others.

\section{Compromises and Adjustments Amidst Constancy of Spark}

Due to the negative feelings brought about by the conflicts and inconsistencies with their families, groups, and selves, the participants would often resort to one or more compromises in order to adapt to their environments. Based on their accounts, the participants' primary ways of dealing with interpersonal and intrapersonal changes are (a) changing of groups, (b) periods of inactivity, and (c) identification of 
another way of expressing their sparks. Nevertheless, it is noteworthy that their religious sparks remain constant despite these adjustments.

Because of conflicts, issues, and other practical reasons (e.g., distance from one's residence), some participants would choose to leave their groups and join another that is similar to the previous one. This decision is also affected by their desire of widening or expanding their knowledge and experience about their religious sparks: "I want to experience more, I want to see myself not only as a lector, not only inside the church, I want to try what is outside." Periods of inactivity were also observed in the participants' accounts wherein the expression of religious sparks is lessened or postponed for some time in order to balance their priorities and responsibilities in life. Note that this is different from totally eliminating one's spark: "You set it aside, hidden, covered but it is still there..." Lastly, the participants were able to identify other means of expressing their sparks, relating it to various fields of expertise such as architecture, education, history, and photography. One participant said that he took architecture in college because of his dream of renovating their parish church: "I wanted to take architecture...I wanted to renovate our church..." Although some participants are thinking of becoming a priest, almost all of them expressed their desire to teach religious education someday. In fact, six out of the eleven participants are taking education as their undergraduate degree. Noticeable in their accounts was the tint of their sparks in all their activities, both in religious or non-religious settings and situations.

\section{DISCUSSION}

The five overarching themes and their subthemes generated through IPA clearly illustrate the complexities and nuances of the lived experiences of Filipino adolescents with religious sparks, their interaction with their families, social groups, and selves, as well as its positive and negative effects on them. Several points can be deduced from the results of this qualitative study that have pertinent implications in the promotion of thriving as well as religiosity and spirituality in the lives of adolescents, particularly those belonging to collectivist cultures (Markus and Kitayama, 1991) such as the Philippines.

\section{Internalizing and Externalizing Nature of Religious Sparks}

As reflected in the results of this paper, religious sparks have been found to provide participants with identities that are both internally 
(self-imposed) and externally (other-imposed) given. They described their religious sparks as entailing a large part of who they are, treating them as central aspects of their personality or self-system. This is congruent with the propositions laid out by several authors regarding the vital role of religion and spirituality in facilitating identity formation among adolescents (Furrow et al., 2004; Erikson, 1964, 1965, \& 1968, as cited in King, 2003; King, 2003; King \& Benson, 2006; Roeser, Issac, Abo-Zena, Brittian, \& Peck, 2008). Considering that resolution and establishment of one's identity is the key developmental task of adolescence (King, 2003; Lerner, 2004, as cited in King et al., 2013), the roles religion and spirituality play are unique in that they provide distinct beliefs, ideologies, moralities, and values where a young person can build his or her own personal and collective identities.

Religious sparks allowed the participants to have a concise description of who they are, where they are good at, and what they are capable of doing. They were able to locate their personal niche in a world full of endless options and possibilities. Aside from that, explanations provided by the teachings and doctrines of their religion have allowed them to answer why they do such things, the reasons behind their religious sparks. Religious beliefs, practices, and traditions are considered valuable existential resources as they address questions relating to one's meaning and purpose in life (King \& Benson, 2006). The existential answers provided by most world religions are crucial in the resolution of identity crisis during the adolescent stage (Erikson, 1964, 1965, \& 1968, as cited in King, 2003). It should be noted that few other institutions like religion promote the values of altruism, forgiveness, selflessness, as well as having a sense of connection with something greater or larger than one's self, all of which are salient in promoting thriving (King et al., 2013; Lerner, Alberts, Anderson, \& Dowling, 2006).

\section{Thriving Through Transcendence}

Affirmation of one's identity through religion and spirituality has been found to play a significant role in the promotion of adolescent thriving and well-being (Furrow et al., 2004; Larson et al., 2006; Roeser et al., 2008). As Lerner and his colleagues (2003) pointed out, this is primarily because of the moral and civic identities provided by most world religions allowing the young person to move beyond self, to consider others, fuelling a commitment to make a significant contribution to his or her family, community, and society. This transcendent or spiritual sensibility found in adolescent thriving (Benson \& Scales, 2009; King \& Benson, 2006) allows the young person 
to see the bigger picture of his or her environment, to include the "we" in the "me." Here, attention is not only placed on the self but on others as well. The same transcendent or spiritual quality is also reflected in how the participants perceive the sources of their religious sparks, namely, from God (external source) and from themselves (internal source). Likewise, this view is similar to their self-imposed (internal) and other-imposed identities (external). Religious sparks have allowed the participants to move beyond themselves, to place themselves in a larger context that includes relationships with the Divine and other people. This is in line with the proposition of Markus and Kitayama (1991) that people from Asian countries are more likely to construe their identities based on their relationships with others, affecting their cognitions, emotions, and motivations. Similarly, this sense of the self provides a sense of embeddedness or connection with something greater or larger than one's self, pointing to the core characteristic of spirituality. It is also noteworthy that the participants themselves made no distinction or differentiation between religiosity and spirituality, supporting the view that the two terms almost always overlap with each other (Hill et al., 2000, as cited in Pargament et al., 2013), particularly here in the Philippines where they are intertwined (Mansukhani \& Resurreccion, 2009; Yabut, 2013). For the participants, their sparks, anchored in the beliefs, practices, and tradition of their religion, is the path that facilitates closeness or connection with a Higher Being, the very definition of spirituality. Hence, a mixture of both religiosity and spirituality can be seen as one of the basic characteristics of religious sparks.

\section{Positive and Negative Effects of Religious Sparks}

Although the participants have generally associated their religious sparks with positive and beneficial experiences, it is still important to acknowledge and examine their negative and adverse effects so as to arrive at a fuller understanding of the phenomenon being studied. The positive and negative experiences narrated by the participants clearly show the multivalent characteristic of religiosity and spirituality as proposed by Pargament and his colleagues (2013) in the integrative paradigm of religion and spirituality. It is an affirmation that both constructs can be helpful and harmful to a higher or lesser degree depending on specific situations. King and Benson (2006) as well as Wagener and Malony (2006) acknowledged that religious engagement can sometimes become dysfunctional and even pathological among children and adolescents. This usually results in the lack of integration of normal developmental competencies including cognitive, 
emotional, social skills. In the context of the current study, some of the participants encountered conflicts with their families, groups, and selves, incurring feelings of being different and alone, discrimination, as well as fear and despair. On the far end of the continuum, two of the eleven participants eventually dropped out of school because they were not able to prioritize their studies due to their religious sparks. Both of them acknowledged that it was primarily because of their excessive and disproportionate dedication or commitment to activities related to their religious sparks. This finding is quite contrasting with the findings of several empirical studies highlighting the positive relationship of religiosity and spirituality with school engagement and academic achievement (Benson, Scales, Sesma, \& Roehlkepartain, 2005; Dowling et al., 2004; Good \& Willoughby, 2011; King \& Benson, 2006; Regnerus \& Elder, 2003, as cited in King et al., 2013; Lerner et al., 2006). The next section attempts to explain this finding in the light of the participants' familial relationships.

\section{Salience of Familial Acceptance and Support in the Thriving Process}

A closer analysis of the negative effects of religious sparks including the conflicts that the participants encountered leads one to the vital role that their families, particularly their parents, played in the expression of their deepest interest or passion in life. Boyatzis, Dollahite, and Marks (2006) highlighted the important role of families in young people's religious and spiritual development stating that "family spirituality and religiosity are linked with many desirable outcomes and inversely with negative outcomes in children and youth" (p. 297). Accordingly, it is in the family where one's religious and spiritual senses are implanted, nurtured, and supported by one's parents or other parental figures. Religious and spiritual discussions, practices, and traditions in the family facilitate this development and their quality and content eventually affect an individual's perception of God, religion, and transcendence. Hence, it was noted by Mahoney (2010, as cited in Mahoney, 2013) that adolescents who have dissimilar or conflicting beliefs with their parents tend to experience greater relationship dissatisfaction as well as religious and/or spiritual struggles. Conversely, greater dialogue on religious and/or spiritual matters between parents and adolescents has been associated with greater use of collaborative methods in resolving conflicts in the family (Brelsford \& Mahoney, 2008, as cited in Mahoney, 2013).

Going back to the results of the study, it was observed that the participants associated negative experiences with the absence of 
affirmation and appreciation of their religious sparks as well as rejection from significant people in their lives. Analyzing the qualitative accounts of the two participants who eventually dropped out of school, one can say that there was really insufficient support and encouragement coming from their families, particularly from their parents. Fear and anxiety prompted them to hide the expression of their religious sparks noting that they do not want to be punished by being prohibited from going to church since they consider this activity as an important aspect of their lives. Unlike other participants, both of them described their parents as non-religious, making them feel misunderstood most of the time. One of them reported having conflicts with his father who has a different religion. The other one said that his parents, including his elder siblings, are always busy at work, making them uninterested in his religious spark. Both of these cases highlight the vital and crucial role that a family plays in the thriving process, even more important than what the researchers expected.

\section{Experiencing Thriving in a Collectivist Culture}

Although their social groups support and encourage the expression of their religious sparks, the participants noted that they cannot feel the same affection and appreciation at home. The lack of guidance from their parents and the experience of frequent conflicts with their families might have contributed to their failure to prioritize their studies. Although it is true that social groups can supplement the affection and appreciation that one's family cannot provide, its role as the primary and necessary source of support, guidance, and encouragement can never be replaced or substituted by one's group members or leaders. Boyatzis and his colleagues (2006) stated that "even if it takes a village to raise a child, the family is surely the first village of religious and spiritual development" (p. 298). Several studies, both local (Cruz, Laguna, \& Raymundo, 2002; Jocano, 1967; Mansukhani \& Resurreccion, 2009; Porio, Lynch, \& Hollnsteiner, 1975, as cited in Mansukhani \& Resurreccion, 2009) and international (Boyatzis et al., 2006; Hershberg et al., 2014; King et al., 2005; Lerner et al., 2011; Mahoney, 2013; Mahoney \& Cano, 2014; Verma \& Sta. Maria, 2006) have affirmed the primacy of the family as the first socialization agent in the development of religiosity and spirituality among children and adolescents.

The Philippines' collectivist culture can also shed some light on this finding. Filipinos, like other people from Asian countries, are known for their close family ties and more often than not, the self is construed based on an individual's relationship with significant 
people, particularly one's family members and close relatives. Here, a person's cognition, emotion, and motivation are affected by how he or she interprets the thoughts, feelings, and actions of others (Markus \& Kitayama, 1991). Thus, the development of meaningful relationships and interactions with parents or other parental figures may be considered crucial in facilitating transcendence among Filipino young people. Based on the results of this study, one can say that unconditional familial acceptance and support are fundamental requirements for Filipino adolescents with religious sparks to thrive and make significant contributions to their families, groups, and selves.

\section{Religious and Spiritual Path of Thriving}

This discussion would be incomplete without mentioning the religious and spiritual path towards adolescent thriving. Thriving's basic tenet rests on the bi-directional interplay between the individual and his or her ecological context wherein both spheres mutually benefit from and contribute to each other (Benson \& Scales, 2009; Lerner et al., 2011; Scales et al., 2011). Here, not only does the environment adjust to support the individual, the individual also adjusts to support the environment. Developmental scientists have provided evidence on the positive association between adolescent religiosity and spirituality as well as thriving outcomes (Good \& Willoughby, 2011; Good et al., 2009; King \& Benson, 2006; King et al., 2013; Larson et al., 2006). Both constructs are positively correlated with physical and mental health (Cotton, Zebracki, Rosenthal, Tsevat, \& Drotar, 2006, as cited in King et al., 2013) and negatively correlated with risky and problematic behaviors (Bridges \& Moore, 2002, as cited in King et al., 2013). In this study, the participants noted that their religious sparks prevented them from delinquency and other negative behaviors, including suicide. It also acts as their source of strength in times of challenges and difficulties in life. These findings are supported by several authors stating that religiosity and spirituality are potent sources of resilience and strength among young people particularly in times of adversities, disadvantages, and traumas through the formation of human adaptive systems that provide social support and attachment relationships (Crawford, Wright, \& Masten, 2006; Good et al., 2009; Pearce, Little, \& Perez, 2003, as cited in King et al., 2013). Sta. Maria (2002, as cited in Verma \& Sta. Maria, 2006) noted that Southeast Asian adolescents see traditional religious practices as a soothing relief from the stresses and strains of living in a fast-paced world. The increasing religious participation of young people in these countries may be seen as an 
indication of their growing dissatisfaction with current societal conditions.

As mentioned, the positive effect of thriving does not only reside within the individual, it goes beyond the self and transcends to the young person's ecologies - his family, his groups, and his society. In this study, the participants made mention of their religious sparks as something to be shared. For them, their talents ought to be used in serving other people, especially those who are in need. They see the teachings and doctrines of their religion (e.g., love your neighbor as yourself, do unto others what you want others do unto you) as well as the examples of Christ and the saints as inspiration and motivation for them to be of service to others. Lerner and his colleagues (2006) as well as King and Benson (2006) emphasized this distinct characteristic of religious ideologies and principles in promoting moral and civic identities among its young members. An analysis of the participants' accounts reveals that their significant contributions to their groups are the activities and programs that they have suggested and implemented as well as the shared knowledge and expertise to the younger or newer members. This is a clear evidence of what Boyatzis and his colleagues (2006) call "generative spirituality" wherein older members of a particular religious group become concerned with the spiritual welfare of the younger ones, giving them care, instruction, and support. In so doing, young people become active agents of their religious groups. This result is not surprising since religion and spirituality have always been associated with increased altruism and civic engagement among adolescents as observed in their attitudes and behaviors (Benson \& Scales, 2009; Furrow et al., 2004; Bundick, Yeager, King, \& Damon, 2010, as cited in King et al., 2013; Lerner et al., 2006).

\section{Future Trajectories: Some Theoretical and Practical Implications}

Verma and Sta. Maria (2006) have acknowledged the challenges that young people are currently facing, including those that pertain to identity, meaning, purpose, and other existential concerns. Changes in the macro (e.g., globalization, migration, technological advances, and urbanization) and micro (e.g., identity formation as well as familial, peer, and school interpersonal relationships) levels that occur within adolescents' ecologies continue to affect and shape their physical, emotional, psychological, as well as spiritual developments. As they face the inevitability of these changes, exposing them to myriad sets of experiences, psychosocial support from significant individuals becomes crucial, including those that come from faith- 
based institutions. During this critical developmental period, religion and spirituality become valuable sources of strength, resilience, meaning, and identity, minimizing possible involvement in risky and problematic behaviors. But more than the preventive role of these constructs, religiosity and spirituality have the powerful potential of promoting thriving. A young person does not only attain adequate developmental competencies but he or she becomes a productive and valuable member of his or her ecological context, capable of providing significant and meaningful contributions to others. Taking into account the deep-seated religiosity and spirituality of Filipinos (Jocano, 1967; Yabut, 2013), parents, teachers, and leaders of youth groups, especially those affiliated with religious institutions, may consider young people's interest or inclination towards such matters as valuable opportunities to promote altruism, civic engagement, prosociality, and resilience. Allotting activities that facilitate transcendence may also be useful for secular or non-religious youth groups in promoting thriving.

The results of this study highlight the importance of identifying one's sparks and allowing it to be honed and developed by concerned adults. The participants' qualitative accounts have provided an indepth understanding of how adolescent thriving occurs in faithbased developmental contexts embedded in a collectivist culture. The findings also expounded the transcendental and multivalent nature of religious sparks, highlighting the salience of acceptance and support from one's family. As such, leaders of social groups as well as family members, especially parents or other parental figures, should work closely together in supporting, encouraging, and developing a young person's spark, regardless of its nature, religious or not, leading him or her towards the promising path of thriving.

\section{Recommendations for Future Research}

Because the composition of the participants of this study is homogeneously small (i.e., all of them are male Filipino Roman Catholics), future researchers may consider increasing their sample by including females as well as participants from other religious denominations, particularly those outside the Judeo-Christian tradition. They may also look into the experiences of adolescents with different gender and sexual identities and those who identify themselves as spiritual-but-not-religious. Furthermore, since this paper focused on the second half of the adolescent period, including participants from early adolescence and early adulthood (some researchers would refer to this as "emerging adulthood") would yield a richer and fuller report on the role of religiosity and spirituality in 
facilitating thriving. Another methodological limitation that future studies may address is the sole reliance of the researcher on the subjective accounts of the participants. Interviewing young people's parents, peers, teachers, and social group leaders may serve as a way of triangulating their accounts on thriving. Nevertheless, the experiential accounts of these highly religious male participants provide valuable and singular insights as local and international demographics affirm the prevalence of religiosity and spirituality among female adolescents. Indeed, much work needs to be done on this area of psychology and its implications on individual and societal development warrant its necessity and importance. Subsequent researches should continuously examine the dynamics of adolescent thriving within specific cultures and belief systems that take into account the influence of one's family, social groups, and peers.

\section{ACKNOWLEDGEMENT}

I would like to acknowledge the assistance of Ciara Janica T. Zalameda in coding and thematizing the participants' interview protocols. I would also like to thank Dr. Judith M. De Guzman and Dr. Belinda V. De Castro for their valuable inputs in improving this qualitative paper. Lastly, my heartfelt gratitude goes to the eleven participants who agreed to be interviewed in this research.

\section{REFERENCES}

Benson, P. L., Roehlkepartain, E. C., \& Rude, S. P. (2003). Spiritual development in childhood and adolescence: Toward a field of inquiry. Applied Developmental Science, 7(3), 205-213. doi:10.1207/S1532480XADSo703_12

Benson, P. L., \& Scales, P. C. (2009). The definition and preliminary measurement of thriving in adolescence. The Journal of Positive Psychology, 4(1), 85-104. doi:10.1080/17439760802399240

Benson, P. L., Scales, P. C., Sesma, A. J., \& Roehlkepartain, E. C. (2005). Adolescent spirituality. In K. A. Moore, L. H. Lippman, K. A. Moore, \& L. H. Lippman (Eds.), What do children need to flourish: Conceptualizing and measuring indicators of positive development (pp. 25-40). New York, NY, US: Springer Science + Business Media. doi:10.1007/0-387-23823-9_3

Bowers, E. P., Geldhof, G. J., Johnson, S. K., Lerner, J. V., \& Lerner, R. M. (2014). Special issue introduction: Thriving across the 
adolescent years: A view of the issues. Journal of Youth and Adolescence, 43(6), 859-868. doi:10.1007/s10964-014-0117-8

Boyatzis, C. J., Dollahite, D. C., \& Marks, L. D. (2006). The family as a context for religious and spiritual development in children and youth. In E. C. Roehlkepartain, P. E. King, L. Wagener, \& P. L. Benson (Eds.), The handbook of spiritual development in childhood and adolescence (pp. 297-309). Thousand Oaks, CA, US: Sage Publications, Inc.

Braun, V., \& Clarke, V. (2006). Using thematic analysis in psychology. Qualitative Research in Psychology, 3(2), 77-101. doi:10.1191/1478088706qpo63oa

Catholic Educational Association of the Philippines. (2013). The National Filipino Catholic Youth Study 2013: Its Joys and Hopes. Retrieved from http://www.ceap.org.ph/upload/ download/201410/7114053166_1.pdf

Crawford, E., Wright, M. O., \& Masten, A. S. (2006). Resilience and spirituality in youth. In E. C. Roehlkepartain, P. E. King, L. Wagener, \& P. L. Benson (Eds.), The handbook of spiritual development in childhood and adolescence (pp. 355-370). Thousand Oaks, CA, US: Sage Publications, Inc.

Cruz, G., Laguna, E., \& Raymundo, C. (2002). Family influences on the lifestyle of the Filipino youth. Philippine Population Review, 1, 3963. Retrieved from http://www.eastwestcenter.org/fileadmin/ stored/pdfs/POPwp10808.pdf

Dowling, E. M., Gestsdottir, S., Anderson, P. M., von Eye, A., Almerigi, J., \& Lerner, R. M. (2004). Structural relations among spirituality, religiosity, and thriving in adolescence. Applied Developmental Science, 8(1), 7-16. doi:10.1207/S1532480XADSo801_2

Eatough, V., \& Smith, J. A. (2008). Interpretative phenomenological analysis. In C. Willig \& W. Stainton-Rogers (Eds.), The SAGE handbook of qualitative research in psychology (pp. 179-194). Thousand Oaks, CA, US: Sage Publications, Inc.

Furrow, J. L., King, P. E., \& White, K. (2004). Religion and positive youth development: Identity, meaning, and prosocial concerns. Applied Developmental Science, 8(1), 17-26. doi:10.1207/ S1532480XADSo801_3

Good, M., \& Willoughby, T. (2011). Evaluating the direction of effects in the relationship between religious versus non-religious activities, academic success, and substance use. Journal of Youth \& Adolescence, 4O(6), 680-693. doi:10.1007/s10964-010-9581-y

Good, M., Willoughby, T., \& Fritjers, J. (2009). Just another club? The distinctiveness of the relation between religious service attendance and adolescent psychosocial adjustment. Journal of 
Youth \& Adolescence, 38(9), 1153-1171. doi:10.1007/s10964-0089320-9

Hershberg, R. M., DeSouza, L. M., Warren, A. A., Lerner, J. V., \& Lerner, R. M. (2014). Illuminating trajectories of adolescent thriving and contribution through the words of youth: Qualitative findings from the 4-H Study of Positive Youth Development. Journal of Youth and Adolescence, 43(6), 950-970. doi:10.1007/ s10964-014-0102-2

Jocano, F. L. (1967). Filipino Catholicism: A case study in religious change. Asian Studies: Journal of Critical Perspectives on Asia, 5(1), 42-64. Retrieved from http://www.asj.upd.edu.ph/ mediabox/archive/ASJ-05-01-1967/jocano-filipino-catholicismcase-study-religious-change.pdf

King, P. E. (2003). Religion and identity: The role of ideological, social, and spiritual contexts. Applied Developmental Science, 7(3), 197204. doi:10.1207/S1532480XADSo703_11

King, P. E., \& Benson, P. L. (2006). Spiritual development and adolescent well-being and thriving. In E. C. Roehlkepartain, P. E. King, L. Wagener, \& P. L. Benson (Eds.), The handbook of spiritual development in childhood and adolescence (pp. 384398). Thousand Oaks, CA, US: Sage Publications, Inc.

King, P. E., Dowling, E. M., Mueller, R. A., White, K., Schultz, W., Osborn, P., . . . Scales, P. C. (2005). Thriving in adolescence: The voices of youth-serving practitioners, parents, and early and late adolescents. The Journal of Early Adolescence, 25(1), 94-112. doi:10.1177/0272431604272459

King, P. E., Ramos, J. S., \& Clardy, C. E. (2013). Searching for the sacred: Religion, spirituality, and adolescent development. In K. I. Pargament, J. J. Exline, \& J. W. Jones (Eds.), APA handbook of psychology, religion, and spirituality: Context, theory, and research (Vol. 1, pp. 513-528). Washington, DC, US: American Psychological Association. doi:10.1037/14045-028

Larson, R. W., Hansen, D. M., \& Moneta, G. (2006). Differing profiles of developmental experiences across types of organized youth activities. Developmental Psychology, 42(5), 849-863. doi:10.1037/0012-1649.42.5.849

Lerner, R. M., Alberts, A. E., Anderson, P. M., \& Dowling, E. M. (2006). On making humans human: Spirituality and the promotion of positive youth development. In E. C. Roehlkepartain, P. E. King, L. Wagener, \& P. L. Benson (Eds.), The handbook of spiritual development in childhood and adolescence (pp. 60-72). Thousand Oaks, CA, US: Sage Publications, Inc.

Lerner, R. M., Dowling, E. M., \& Anderson, P. M. (2003). Positive 
youth development: Thriving as the basis of personhood and civil society. Applied Developmental Science, 7(3), 172-180. doi:10.1207/S1532480XADSo703_8

Lerner, R. M., Lerner, J. V., von Eye, A., Bowers, E. P., \& LewinBizan, S. (2011). Individual and contextual bases of thriving in adolescence: A view of the issues. Journal of Adolescence, 34(6), 1107-1114. doi:10.1016/j.adolescence.2011.08.001

Lerner, R. M., von Eye, A., Lerner, J. V., Lewin-Bizan, S., \& Bowers, E. P. (2010). Special issue introduction: The meaning and measurement of thriving: A view of the issues. Journal of Youth and Adolescence, 39(7), 707-719. doi:10.1007/s10964-010-9531-8

Mahoney, A. (2013). The spirituality of us: Relational spirituality in the context of family relationships. In K. I. Pargament, J. J. Exline, \& J. W. Jones (Eds.), APA handbook of psychology, religion, and spirituality: Context, theory, and research (Vol. 1, pp. 365389). Washington, DC, US: American Psychological Association. doi:10.1037/14045-020

Mahoney, A., \& Cano, A. (2014). Introduction to the special section on religion and spirituality in family life: Pathways between relational spirituality, family relationships and personal well-being. Journal of Family Psychology, 28(6), 735-738. doi:10.1037/famooooo41

Mansukhani, R., \& Resurreccion, R. (2009). Spirituality and the development of positive character among Filipino adolescents. Philippine Journal of Psychology, 42(2), 271-290.

Markus, H. R., \& Kitayama, S. (1991). Culture and the self: Implications for cognition, emotion, and motivation. Psychological Review, 98(2), 224-253. doi:10.1037/0033-295X.98.2.224

Pargament, K. I., Mahoney, A., Exline, J. J., Jones, J. W., \& Shafranske, E. P. (2013). Envisioning an integrative paradigm for the psychology of religion and spirituality. In K. I. Pargament, J. J. Exline, \& J. W. Jones (Eds.), APA handbook of psychology, religion, and spirituality: Context, theory, and research (Vol. 1, pp. 3-19). Washington, DC, US: American Psychological Association. doi:10.1037/14045-001

Philippine Statistics Authority. (2016). Philippines in figures. Retrieved from https://psa.gov.ph/sites/default/files/PIF\%2O 2016.pdf

Roeser, R. W., Issac, S. S., Abo-Zena, M., Brittian, A., \& Peck, S. C. (2008). Self and identity processes in spirituality and positive youth development. In R. M. Lerner, R. W. Roeser, \& E. Phelps (Eds.), Positive youth development and spirituality: From theory to research (pp. 74-105). West Conshohocken, PA, US: Templeton 
Foundation Press.

Scales, P. C., Benson, P. L., \& Roehlkepartain, E. C. (2011). Adolescent thriving: The role of sparks, relationships, and empowerment. Journal of Youth and Adolescence, 4O(3), 263-277. doi:10.1007/ s10964-010-9578-6

Seligman, M. P., \& Csikszentmihalyi, M. (2000). Positive psychology: An introduction. American Psychologist, 55(1), 5-14. doi:10.1037/0003-066X.55.1.5

Smith, J. A., \& Eatough, V. (2007). Interpretative phenomenological analysis. In E. Lyons \& A. Coyle (Eds.), Analysing qualitative data in psychology (pp. 35-50). Thousand Oaks, CA: Sage Publications Ltd.

Smith, J. A., \& Osborn, M. (2003). Interpretative phenomenological analysis. In J. A. Smith (Ed.), Qualitative psychology: A practical guide to research methods (pp. 51-80). Thousand Oaks, CA, US: Sage Publications, Inc.

Social Weather Stations. (2017). First Quarter 2017 Social Weather Survey:48\%ofFilipinoadultsattendreligiousservicesweekly;85\% said religion is important. Retrieved from https://www.sws.org. $\mathrm{ph} /$ swsmain/artcldisppage/?artcsyscode $=$ ART-20170413105521

Verma, S., \& Sta. Maria, M. (2006). The changing global context of adolescent spirituality. In E. C. Roehlkepartain, P. E. King, L. Wagener, \& P. L. Benson, (Eds.), The handbook of spiritual development in childhood and adolescence (pp. 124-136). Thousand Oaks, CA, US: Sage Publications, Inc.

Wagener, L. M., \& Malony, H. N. (2006). Spiritual and religious pathology in childhood and adolescence. In E. C. Roehlkepartain, P. E. King, L. Wagener, \& P. L. Benson (Eds.), The handbook of spiritual development in childhood and adolescence (pp. 137149). Thousand Oaks, CA, US: Sage Publications, Inc.

Yabut, H. J., (2013). Isang paglilinaw sa mga paniniwala at pagpapakahulugan sa ispiritwalidad at relihiyon ng mga Pilipino. DIWA E-Journal, 1(1), 162-179. 